\title{
Titanium Nitride Coatings on Inner Wall of Narrow Tube
}

\author{
by \\ by Yuta Kotani ${ }^{* 1}$,Koichi Hayakawa ${ }^{* 1}$, Tempei Tanakamaru ${ }^{* 1}$ and Yoshihito Matsumura ${ }^{* 2}$
}

(Received on Mar. 31, 2008 and accepted on Jul. 9, 2008)

\begin{abstract}
:
Titanium nitride (TiN) shows considerable hydrogen impermeability and is expected as a hydrogen-impermeable coating of cladding tubes for metal hydride fission fuel. The TiN coating production by the plasma process is very complicated because the cladding tube is not wide enough to create stable plasma. In this study, a simple reactive evaporation process was employed for the coating process of TiN films on the inner wall of a narrow tube. The films were thermally deposited on stainless steel sheets as the substrate and were coiled around the inner wall of silica glass tubes. A Ti wire twisted with a Mo filament was used for the evaporant. As a result, thin films with gold color were obtained. From the XRD measurement of the films, distinct diffraction patterns of TiN phase were observed. A reactivity of $\mathrm{N}_{2}$ gas molecules with Ti atoms in Ti-N film formation was measured quantitatively. The reaction probability of $\mathrm{N}_{2}$ molecules $\mathrm{r}_{\mathrm{N} 2}$ is defined as the ratio of the $\mathrm{N}_{2}$ absorption rate $A_{\mathrm{N} 2}$ on Ti to the rate of $\mathrm{N}_{2}$ impingement $\mathrm{Z}_{\mathrm{N} 2}$. Reactive evaporation process showed $r_{N_{2}} \cong 0.013$. It was $1 / 5$ of $r_{\mathrm{N} 2}$ with Ti films prepared by plasma processes
\end{abstract}

Keyword : Titanium nitride coating, Inner wall of narrow tube, Reactive vacuum evaporation process, prevention coating of hydrogen gas, reaction probability

\section{Introduction}

Narrow tubes are widely used in industry as water pipes, hydrogen gas pipes, cooling pipes for nuclear reactors, etc. However, when these steels are catholically charged with hydrogen at room temperature, their subsurface layers become hard and brittle, and numerous cracks are forms. It is therefore necessary to protect the inside of the tubes. Titanium nitride shows considerable hydrogen impermeability and is expected as a prevention coating of hydrogen gas for a cladding tube of metal hydride fission fuel ${ }^{1-5}$ ). Among various methods of surface modification, plasma nitriding is widely used because it increases hardness and improves wear and fatigue resistance of ferrous and other materials ${ }^{6-9}$ ). However, the coating processes are very complicated because the cladding tube is not wide enough to create stable plasma ${ }^{10)}$. In this study, a simple reactive evaporation process was employed for coating process of TiN films onto the inner wall of narrow tube. The reaction probability $r_{N 2}$ of $\mathrm{N}_{2}$ was used as a measure for assessing the reactivity and the reaction probability $\mathrm{r}_{\mathrm{N} 2}$ of $\mathrm{N}_{2}$ as a measure for assessing the reactivity for reactive vapor deposition process and plasma process ${ }^{11)}$.

*1 Graduate Student, Course of Applied Science,

*2 Professor, Department of Energy Engineering,

\section{Experimental}

The reactive evaporation process was used for Ti-N film formation. The schematic diagram of the evaporation apparatus used for this study is shown in Fig. 1.

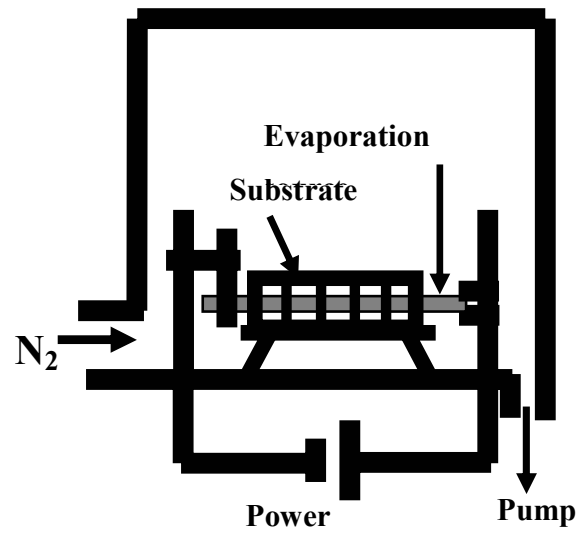

Fig. 1. Schematic of reactive evaporation process

The base pressure of the vacuum chamber was less than $3.0 \times 10^{-4}$ $\mathrm{Pa}$. The films were thermally deposited on stainless steel sheets $(60 \mathrm{~mm} \times 10 \mathrm{~mm})$ as the substrate and were coiled around the inner wall of silica glass tubes (160 $\mathrm{mm}$ inner diameter and $10 \mathrm{~mm}$ long) was set nine pieces in series. The reactive evaporation system was used as the resistance heating process. A twisted Ti wire with a Mo 
filament was used for the evaporant. Nitrogen gas as reactive gas was introduced into the vacuum chamber with a gas pressure of $1.0 \times 10^{-1} \mathrm{~Pa}$. Deposition times were varied as Ti deposition time $300 \mathrm{~s}(5 \mathrm{~min})$ and Ti-N deposition time $900 \mathrm{~s}$ (15 min) (sample Ti-N5/15), Ti deposition time $600 \mathrm{~s}$ (10 min) and Ti-N deposition time $600 \mathrm{~s}$ (10 min) (sample Ti-N10/10), Ti deposition time $600 \mathrm{~s}$ (10 min) and Ti-N deposition time $1200 \mathrm{~s}$ (20 min) (sample Ti-N10/20), respectively. After the film formation, film thickness was confirmed by an observation of film cross sections using a scanning electron microscope (SEM). The compositions of N/Ti in Ti-N films were analyzed by X-ray Photoelectron Spectroscopy (XPS). X-Ray diffraction (XRD) analyses was used for microstructure analysis.

\section{Results and Discussion}

\subsection{Characteristics of $\mathrm{Ti}-\mathrm{N}$ coatings}

Deposited films showed golden color. The results on composition $\mathrm{N} / \mathrm{Ti}$ and thickness conducted under different experimental $\mathrm{Ti}$ evaporation time and Ti-N evaporation times are presented in Table 1. Samples of Ti-N10/10 and Ti-N10/20 showed same thickness of deposition may imply that this film thickness is depended on the deposition time of Ti. The deposition rate of TiN was decreasing with scattering of Ti vapor by nitrogen gas molecules. After evaporation process, the filament showed yellowish gold color with titanium nitride formation. The reason for low deposition rate of $\mathrm{TiN}$ is also due to the decreasing vapor pressure of titanium with surface nitriding of titanium wire. The film composition of all films showed about $\mathrm{N} / \mathrm{Ti}=0.6$. TiN phase shows $\mathrm{TiN} / \mathrm{Ti}=0.56-1.0$ in $\mathrm{Ti}-\mathrm{N}$ phase diagram. The composition of those film samples showed TiN by XPS analysis 12).

Table 1. Evaporation time vs. composition of Ti-N coatings

\begin{tabular}{|c|c|c|c|c|}
\hline Sample & $\begin{array}{c}\text { Ti } \\
\text { evaporation } \\
\text { time }[\mathrm{s}]\end{array}$ & $\begin{array}{c}\text { Ti-N } \\
\text { evaporation } \\
\text { time }[\mathrm{s}]\end{array}$ & $\begin{array}{c}\text { Composition } \\
\mathrm{N} / \mathrm{Ti}\end{array}$ & $\begin{array}{c}\text { Thickness } \\
{[\mu \mathrm{m}]}\end{array}$ \\
\hline Ti-N5/15 & 300 & 900 & 0.65 & 2.5 \\
\hline Ti-N10/10 & 600 & 600 & 0.61 & 3.0 \\
\hline Ti-N10/20 & 600 & 1200 & 0.63 & 3.0 \\
\hline
\end{tabular}

Fig. 2 shows the XRD diffraction patterns of Ti-N films as a function of various samples. Sample Ti-N5/15 shows strong diffraction peak of titanium. And this sample shows weak titanium nitrides peaks and stainless steel as substrate peaks to penetrate film. Sample Ti-N10/20 shows strong diffraction peaks of TiN. And this sample shows strong stainless steel substrate peak to penetrate film and weak titanium peaks. Therefore, sample Ti-N10/20 is a mixed phase of $\mathrm{TiN}$ phase and $\mathrm{Ti}_{2} \mathrm{~N}$ phase. Diffraction peaks of Ti phase were observed as titanium under layer path through the thin TiN top coating.

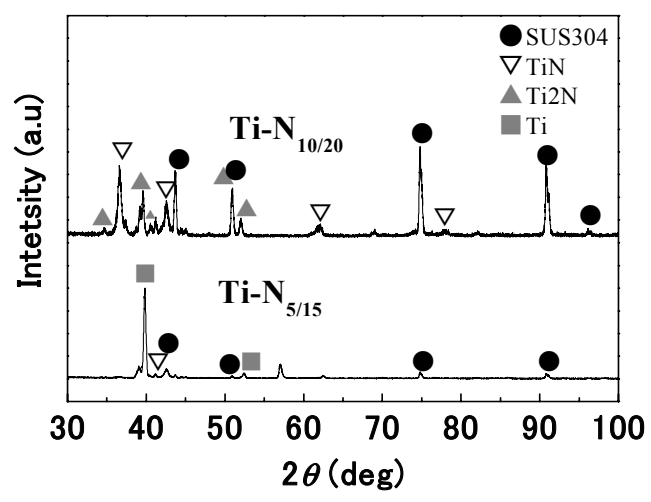

Fig. 2. X-ray diffraction profile of Ti-N thin films prepared at various evaporation times

\subsection{Assessment of the reactivity}

The reaction probability of a gas with a metal is a useful measure to assess the quantitative reactivity of gas involved in the reaction, which has been demonstrated for many metal-gas systems ${ }^{13-15)}$.

The total amount of Ti atoms in film $N_{T i}$ can be derived as follows.

$N_{T i}=\left(V_{T i} \times \rho\right) / M_{T i} \quad[\mathrm{~mol}]$

Where $V_{T i}$ is volume of Ti film, $\rho$ is Ti density and $M_{T i}$ is molecular mass of Ti.

The impinging rate of Ti atoms $Z_{T i}$ is defined as the ratio of the $N_{T i}$ times Avogadro's constant $N_{A}$ to the evaporation time t:

$$
Z_{T i}=\left(N_{T i} \times N_{A}\right) / t \quad\left[\mathrm{~s}^{-1}\right]
$$

The absorbing rate of $\mathrm{N}_{2} A_{N 2}$ on Ti surface can be derived as follows:

$$
A_{N 2}=Z_{T i} \times\{(N / 2) / T i\} \cdot\left[\mathrm{s}^{-1}\right]
$$

The reaction probability of $\mathrm{N}_{2}$ molecules $r_{N 2}$ is defined as the ratio of the absorbing rate of $\mathrm{N}_{2}$ on Ti surface $A_{N 2}$ to the rate of $\mathrm{N}_{2}$ impingement $Z_{N 2}$ :

$$
r_{N 2}=A_{N 2} / Z_{N 2} \text { (1) }
$$

where 
$Z_{N 2}=2.6 \times 10^{24} P_{N 2} /\left(M_{N 2} \times T\right)^{1 / 2}\left[\mathrm{~m}^{-2} \cdot \mathrm{s}^{-1}\right]$.

$\mathrm{T}$ is the absolute temperature, $\mathrm{M}$ is the molar mass and $P_{N 2}$ is $\mathrm{N}_{2}$ partial pressure.

Table 2. shows $A_{N 2}$ of each sample.

Table 2. Absorbing rate of $\mathrm{N}_{2}$ on Ti surface: $\mathrm{A}_{\mathrm{N} 2}$ of samples

\begin{tabular}{|c|c|}
\hline Sample & $\boldsymbol{A}_{N 2}$ \\
\hline Ti-N $_{\mathbf{5 / 1 5}}$ & $\mathbf{0 . 3 7} \times \mathbf{1 0}^{\mathbf{2 0}}$ \\
\hline Ti-N $_{\mathbf{1 0} / \mathbf{1 0}}$ & $\mathbf{0 . 4 3} \times \mathbf{1 0}^{20}$ \\
\hline Ti-N $_{\mathbf{1 0 / 2 0}}$ & $\mathbf{0 . 2 9} \times \mathbf{1 0}^{20}$ \\
\hline
\end{tabular}

Table 3. shows the reaction probability $r_{N 2}$ of samples. For $r_{N 2}=0.010-0.016$, almost same values are obtained. The $r_{N 2}$ with Ti-N films by reactive evaporation process exhibit $r=0.013$.

Table 3. Reaction probability of samples

\begin{tabular}{|c|c|}
\hline Sample & $\begin{array}{r}\text { Reaction } \\
\text { Probability } \quad r_{N 2}\end{array}$ \\
\hline Ti-N $_{5 / 15}$ & 0.013 \\
\hline Ti-N $_{10 / 10}$ & 0.016 \\
\hline Ti-N $_{10 / 20}$ & 0.010 \\
\hline
\end{tabular}

Table 4 shows $r_{N 2}$ on Ti surface for various processes ${ }^{11)}$. In Table 3 and Table 4 , the reaction probability of $\mathrm{N}_{2}$ with Ti film by reactive evaporation process and ARE process exhibit the same value of $r_{N 2}=0.07$.

Table 4. Reaction probability $\mathrm{r}_{\mathrm{N} 2}$ on Ti surface for various processes

\begin{tabular}{|c|c|}
\hline \multirow{2}{*}{ Process } & $\begin{array}{r}\text { Reaction Probability } \boldsymbol{r}_{N 2} \text { at } \\
\text { Composition } \quad \boldsymbol{x}=0.6\end{array}$ \\
\hline ARE Process & 0.07 \\
\hline HCD Process & 0.15 \\
\hline UHV & 0.25 \\
\hline
\end{tabular}

In Table 4, the Ti surface prepared under UHV (Ultrahigh vacuum, $\mathrm{P}<10^{-7} \mathrm{~Pa}$ ) conditions exhibits the highest $\mathrm{N}_{2}$ reactivity, $r_{N 2}=0.25$, even at $x=0.6$. Electron transfer between the surface and $\mathrm{N}_{2}$ molecules is the essential step for the $\mathrm{N}_{2}$ dissociation ${ }^{16)}$. If the surface is covered with residual gaseous $\left(\mathrm{H}_{2} \mathrm{O}, \mathrm{CO}_{2}\right.$ etc $)$ and becomes less metallic, the electron transfer becomes inhibited. In this study, $\mathrm{r}_{\mathrm{N} 2}$ with Ti film by reactive evaporation process exhibits $1 / 5$ of $r_{N 2}$ with Ti film prepared by plasma processes. This is because reactive evaporation process has a larger effect of residual gas than UHV ${ }^{11)}$.

\section{Conclusion}

In this study, a simple reactive evaporation process was employed for coating process of TiN films onto inner wall of narrow tube. The films were thermally deposited on stainless steel sheets as substrate. A twisted Ti wire with a Mo filament was used as evaporant. Thin films with gold color were obtained. A reactivity of $\mathrm{N}_{2}$ gas molecules with $\mathrm{Ti}$ atoms in Ti-N film formation was measured quantitatively.

The $\mathrm{r}_{\mathrm{N} 2}$ with Ti film by reactive evaporation process exhibits $1 / 4$ of $r_{N 2}$ with Ti film prepared by plasma process. Deposited Ti-N films showed golden color and composition of deposited films showed about N/Ti $=0.6$ analyzed by XPS. Therefore, The simple reactive evaporation is very useful for TiN inner wall coating process of narrow tube.

\section{Acknowledgement}

This study was made in the frame of Development of Advanced Production Processes for Energy Conversion Materials, Future Science \& Technology Joint Research Center, Tokai University.

\section{References}

1) K. Konashi and Y. shimada, J. Nucl. Energy, vol. 46, (2004), pp. 457-466.

2) B. Tsuchiya, J. Huang, K. Konashi, M. Teshigawara and M. Yamawaki, Trans. Am. Nucl. Soc., vol. 81, (1999), pp. 125-126.

3) N. Hosoda, H. H. Uchida and E. Fromm, J. Less-Common. Met, vol. 172/174, (1991), pp. 824-831.

4) K. Onooe, K. Saitoh, S. Inayashi and S. Tsukahara, J. Vac. Soc. Jpn, vol. 34, (1991), pp. 420-426.

5) T. Nishikiori, T. Nohira and Y. Ito, J. Electrochem. Soc, vol. 148, (2001), pp. E52-E59.

6) N. Nishida, H. Kamasaki, K. Hoda and N. Hosokawa, J. Met. Finishing Soc. Jpn, vol. 38, (1987), pp. 483-487.

7) P. A. Lindfors, W. M.Mularie and G. K. Wehner, Surf. Coating. Tehnol., vol. 29, (1986), pp. 275-290.

8) Y. Matsumura, T. Yoshioka and Y. C. Huang, Proc. nt.Ion Eng.Cong., Japan, 1983, pub. by Nippon Denki Gakkai, pp.1283. 
9) A. K.Suri, R. Nimmagadda and R. F. Bunshah, Thin Solid Films, vol. 72, (1980), pp. 529-533.

10) T. Nagano and H. Fujiyama, Jpn. J. Appl. Phys., vol. 38, (1999), pp. 4338-4341.

11) Y. Matsumura, T. Chujo and H. Uchida, Surf. Coating Technol, vol. 60, (1993), pp. 489-492.

12) Binary Ally Phase Diagrams second Edition, Hiroaki Okamoto, Thaddeus B. Massalski, P.R Subramanian and Linda Kacprzak. (Materials Park, Ohio 1990), pp. 2707.

13) S. Hofmann, Thin Solid Films, vol. 193-194, (1990), pp. 648-664.

14) Y. Matsumura, H. Uchida and Y. C. Huang, Proc. Plasma Surf. Eng., Garmish-Partenkirchen, FRG, 1988, pub. by Deutsche Gesellschaft für Metallkunde, vol.1, pp.45.

15) E. From,V.Grajewski and H. H. Uchida, Proc. Plasma Surface Enginnering, Gamish-Parten kirchen, FRG,1998, pub.by Deutsche Gesellscharft für Metallkunde, vol.1, pp.37.

16) J. K. Norskov, J. Less-Common Met., vol. 130, (1987), pp. 475-490. 